\title{
EVALUATION OF ASPHALT MIXES CONTAINING RAP COMPARED WITH CONVENTIONAL MIXES
}

\author{
Azzam A. Alkhalil ${ }^{1}$, Laila S. Radwan ${ }^{2}$ and Mohamed R. Elmitiny ${ }^{2}$ \\ ${ }^{1}$ M.Sc. in Civil Engineering (2010) - Cairo University - Egypt \\ ${ }^{2}$ Highway and Traffic, Engineering, Public Works Department, Faculty of Engineering \\ Cairo University
}

ABSTRACT

Using Reclaimed Asphalt Pavement (RAP) in asphalt mixes has become a common practice in many countries. Experience indicated that the recycling of asphalt pavements is very advantageous from different perspectives. Some of the advantages of utilizing RAP include conservation of asphalt and aggregate resources, conservation of energy and reduction in lifecycle cost $[5,6,7]$. In this study, the suitability of asphalt mixes using RAP was investigated. Three hot asphalt mixes were prepared following gradations recommended by the Egyptian code of specifications. Marshall Mix design procedure was used to determine the optimum asphalt content. The first mix was composed of $100 \%$ fresh aggregate and virgin asphalt, the second mix was composed of 25\% RAP and $75 \%$ fresh aggregates and virgin asphalt, and the third mix was composed of $40 \%$ RAP and $60 \%$ fresh aggregates and virgin asphalt. The results indicated that the bulk density increase with the increasing of the percentage of RAP in mix B, while increasing in RAP results decreases in Air Voids and flow values. Furthermore, the stability is changed from $2325 \mathrm{lb}$ for the control mix to $2175 \mathrm{lb}$ and $1829 \mathrm{lb}$ for mixes with $25 \%$ and $40 \%$ RAP respectively. Comparing the results of the conducted tests indicated that the use of RAP in Hot Mix Asphalt (HMA) was advantageous in all properties measured, but the results are acceptable by Egyptian code specifications. The results of Marshall Properties indicate that the amount of new binder that needs to be added to the RAP mixture can be reduced without significant effects on the quality of the produced mix. Therefore, it is preferred to use mixes containing RAP in highways with studied proportions [1].

(C) 2014 Faculty of Engineering, Al-Azhar University, Cairo, Egypt. All rights reserved.

\section{Keywords: Hot Mix Asphalt (HMA), Reclaimed Asphalt Pavement (RAP), Marshall Properties, and Stability.}

\section{INTRODUCTION}

The resulting materials during roadways maintenance and rehabilitation activities are usually known as Reclaimed Asphalt Pavements (RAP), which is normally produced by milling existing asphalt pavements or crushing materials resulting from old asphalt pavements removal. Since most of roadways are constructed using high-type bituminous pavements, RAP materials, if properly processed, will consist of high quality, well graded asphalt coated aggregates. RAP can be used in many highway construction applications as an aggregate substitute and asphalt cement supplement in recycled asphalt paving (hot mix or cold mix). In addition, it can be used as a granular base or subbase, stabilized base aggregate or as an embankment or fill material [9].

In the United States, for example, and according to documents published by the National Asphalt Pavement Association (NAPA), the Federal Highway Administration (FHWA) estimates that out of the 90 million tons of Hot Mix Asphalt (HMA) milled and removed each 
year, $90 \%$ is reused in highway applications in one form or another, including pavements, subbase and fill. About 1/3 of the 90 million tons is recycled into HMA [7,10].

A number of researchers pointed out that the properties of the recycled mixtures are believed to be influenced by the properties of the aged binder in RAP and the amount of RAP in the mixture. They also indicated that the amount of RAP used in the recycled mixture depends on the type of hot mix plant being used for preparing the mix, environmental considerations and gradation of the aggregate in RAP, especially the material passing \#200 $(0.075 \mathrm{~mm})$ sieve size. Due to the various and obvious advantages of using RAP, many state highway agencies are moving toward rising the percentages of RAP in their hot-mix asphalt pavements. RAP has been used in hot mix asphalt pavements in various percentages that reached in some cases up to $80 \%$, and most usually from $20-50 \%[9,11]$.

Amongst various pavement recycling methods, hot mix recycling has certain advantages, such as, comparable performance to that of conventional mixes [1] and better quality control [8]. This is due to the fact that constituents are mixed under controlled conditions and it is possible to monitor mixing process continuously. In this process, less workspace is required for laying the recycled mix. Hence, this is suitable for the roads where the right-of-way is restricted.

\section{OBJECTIVES}

The main objective of the research is to evaluate the effects of partial replacement of aggregates by RAP on the mechanical response of bituminous mixtures are as follows:

- To determine the basic engineering properties of the Virgin bitumen and Virgin aggregate and the basic engineering properties of Reclaimed Aggregate and binder after extraction and Recovery.

- To carry out the blending of RAP and Virgin aggregates for $25 \%$ and $40 \%$ RAP content by Marshall design method.

- To workout the economics of recycling of bituminous pavement materials, comparing with conventional virgin mixes.

\section{STUDY APPROACH AND METHODOLOGY}

In order to achieve the objective of this study, the following suggested approach was followed. Using the recommended gradation (3D), three different hot asphalt mixes were prepared and compared. The basis of assessment is to use standard procedures described by the American Society of Testing and Materials (ASTM), and the American Association of State Highway and Transportation Officials (AASHTO), to measure some properties of the three hot asphalt concrete mixes, and then to compare their properties. The proceeding text provides detailed description of the adapted procedure $[2,3,4]$.

\section{MATERIALS AND METHODS OF TESTING}

\subsection{Fresh Aggregates and Binder}

One coarse aggregate type (Crushed Dolomite), one fine aggregate type (Manufactured Sand (MS)), and one mineral filler type (Stone Screening Filler (SF)), and One type of asphalt cement was selected (Suez asphalt cement, 60/70 penetration) obtained from asphalt concrete mixing plant belongs to General Authority for Roads \&Bridges and Land Transport (GARBLT) at Alexandria - Cairo desert Road with the properties described in the following sections, have been used in the study.

\subsection{Reclaimed Asphalt Pavement (RAP)}

The RAP for this study was obtained by processing millings from of maintenance operations carried out by the General Authority for Roads \& Bridges and Land Transport (GARBLT) on the Alexandria - Cairo desert Road at Kilometer 90 approx, these maintenance operations performed on the wear layer which was constructed in 2011because appearance some structural defects on it led to these operations. Representative samples of reasonable sizes from the site were selected following the (ASTM C-702) test procedure. This procedure is crucial to reduce bias due to unforeseen factors that would affect measurements. In order to 
estimate the amount of asphalt in the RAP material, extraction test (ASTM D2172-95) was performed followed by sieve analysis of the clean aggregate $[2,3,4]$.

\subsection{Tests for Material Characterization}

Many laboratory tests have been conducted during the experimental work of this research, these tests have been divided into three categories the first category comprises the tests conducted to evaluate aggregate properties, second category is that tests followed to evaluate asphalt cement properties, and the third is that tests followed to evaluate reclaimed asphalt pavement (RAP) properties as follow;

1. Extraction of Asphalt from RAP [2, 3,4]

2. For fresh and RAP aggregates: Gradation, Los Angeles Abrasion Test, Specific Gravity and Absorption [2, 3,4]

3. For new and old binder: Penetration, Kinematic Viscosity, and Softening Point $[2$, $3,4]$

\subsection{Results of Tests for Material Characterization}

Figure (1) shows the gradation of RAP aggregate and recommended gradation (3D). It can be noticed that RAP aggregate gradation is finer than the median recommended gradation (3D). This is mainly due to the crushing of the aggregates during the milling process, in addition to the aggregate wear that occurs during mixing, compaction and traffic serving of the asphalt concrete mix. Specific gravity and absorption of the RAP aggregate were calculated according to ASTM C127-88 (for coarse aggregates) and ASTM C128-97 (for fine aggregates) test procedures $[2,3,4]$.

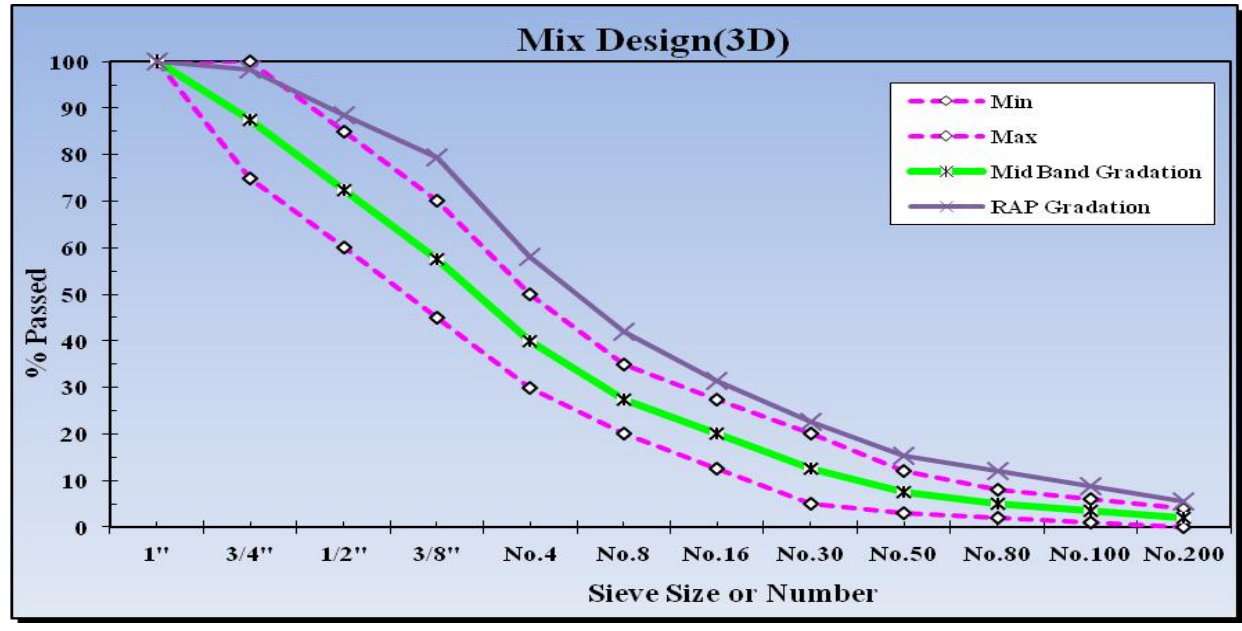

Figure (1): Egyptian specified gradation limits, median gradation, and RAP aggregate gradation Los Angeles Abrasion Test and specific gravity and absorption of coarse and fine aggregates were conducted on fresh and RAP aggregates (see table 1).

Table (1): Properties of Recycled and Virgin Aggregates

\begin{tabular}{|c|c|c|c|c|}
\hline \hline $\begin{array}{c}\text { Aggregate Type } \\
\text { and Designation }\end{array}$ & Los Angeles \% & $\begin{array}{c}\text { Bulk Specific } \\
\text { Gravity }\end{array}$ & $\begin{array}{c}\text { Apparent Specific } \\
\text { Gravity }\end{array}$ & $\begin{array}{c}\text { Water } \\
\text { Absorption \% }\end{array}$ \\
\hline \hline Dolomite (AGG. 2) & 26.20 & 2.587 & 2.674 & 1.20 \\
\hline Dolomite (AGG. 1) & 24.26 & 2.605 & 2.683 & 1.40 \\
\hline $\begin{array}{c}\text { Manufactured Sand } \\
\text { (MS) }\end{array}$ & --- & 2.744 & 2.774 & 0.40 \\
\hline Stone Filler & --- & 2.726 & 3.024 & 3.60 \\
\hline RAP Aggregtes & 28.75 & 2.644 & 2.768 & 1.50 \\
\hline \hline
\end{tabular}

For the study, Bitumen 60/70 grade was considered and their properties were tested for its suitability for the study (Table 2). The bitumen properties were found to satisfy the requirements. 
Table (2): Properties of Virgin Asphalt (60/70)

\begin{tabular}{|c|c|c|}
\hline \hline Test Type; Designation & Result & $\begin{array}{c}\text { Specification Limits for AC, } \\
\mathbf{6 0 - 7 0} \text { Pen. }\end{array}$ \\
\hline \hline Penetration $\left(0.1 \mathrm{~mm}\right.$, at $\left.25^{\circ} \mathrm{C}, 100 \mathrm{gm}, 5 \mathrm{sec}\right)$ & 67 & $60-70$ \\
\hline Kinematic Viscosity $\left(\right.$ centistokes, $\left.135^{\circ} \mathrm{C}\right)$ & 384.40 & $320 \mathrm{~min}$ \\
\hline Ring and Ball Softening Point $\left({ }^{\circ} \mathrm{C}\right)$ & 51 & $45-55$ \\
\hline Specific Gravity & 1.03 & --- \\
\hline \hline
\end{tabular}

Random samples were considered from the RAP for the laboratory tests. The RAP materials were subjected to solvent (benzene) extraction method by centrifuge extractor and the average bitumen content were found to be $3.75 \%$. The asphalt cement of the extracted RAP used in this study was determined and subjected to standard laboratory tests mentioned above to determine its physical properties as shown in table (3).

Table (3): Properties of Asphalt Cement Extracted from RAP

\begin{tabular}{|c|c|c|}
\hline \hline Test Type; Designation & Result & $\begin{array}{c}\text { Specification Limits for AC, 60- } \\
\mathbf{7 0} \text { Pen. }\end{array}$ \\
\hline \hline Penetration $\left(0.1 \mathrm{~mm}\right.$, at $\left.25^{\circ} \mathrm{C}, 100 \mathrm{gm}, 5 \mathrm{sec}\right)$ & 61 & $60-70$ \\
\hline Kinematic Viscosity (centistokes, $\left.135^{\circ} \mathrm{C}\right)$ & 359.60 & $320 \mathrm{~min}$ \\
\hline Ring and Ball Softening Point $\left({ }^{\circ} \mathrm{C}\right)$ & 57 & $45-55$ \\
\hline \hline Asphalt Content \% & & -- \\
\hline \hline
\end{tabular}

\subsection{Preparation of the Asphalt Concrete Mixes}

The gradation results of the RAP materials (Figure 1) suggested that fresh aggregates should be mixed with the RAP material to meet standard recommended gradation. Three asphalt mixes were used to achieve the goals of this study. The first mix, called "Control Mix", was composed of $100 \%$ fresh aggregate and virgin asphalt; while the second mix, was composed of 25\% RAP (aggregate and asphalt), and 75\% fresh aggregates and virgin asphalt, and the third mix was composed of 40\% RAP (aggregate and asphalt), and 60\% fresh aggregates and virgin asphalt. Marshall mix design procedure (ASTM D1559), which is currently used in Egypt for asphalt concrete mix design, was used to determine the optimum asphalt content (that produces $4 \%$ air voids) for the asphalt mixes used in the study [2,3,4]. Marshall stability, flow, voids filled with asphalt and voids in mineral aggregate values were checked to verify that they meet the specification limits of Egyptian code.

\section{RESULTS AND DISCUSSIONS}

As mentioned before, Marshall Mix Design method was used in this study for two purposes first is to determine the optimum asphalt content for each mix and second to empirically evaluate hot asphalt mixes behavior or response. The optimum asphalt content for each mix was determined by selecting the asphalt content corresponding to each of; maximum density, maximum stability, and the optimum air voids (4\%), then averaging these values as described in Table (4).

It is clear from Figure (2, 3, 4,5, and 6), Table (4 and 5), and the statistical analysis that;

1. Mix A (with $0 \%$ RAP) produces $6.90 \%$ and $27 \%$ higher Marshall Stability than that of mix B (with $25 \%$ RAP) and mix C (with $40 \%$ RAP), and this could be attributed to the angularity and roughness in the particles of the fresh aggregates which causes more stability for the mix if it compared to the roundness and smoothness of reclaimed asphalt pavement. 
EVALUATION OF ASPHALT MIXES CONTAINING RAP COMPARED WITH CONVENTIONAL MIXES

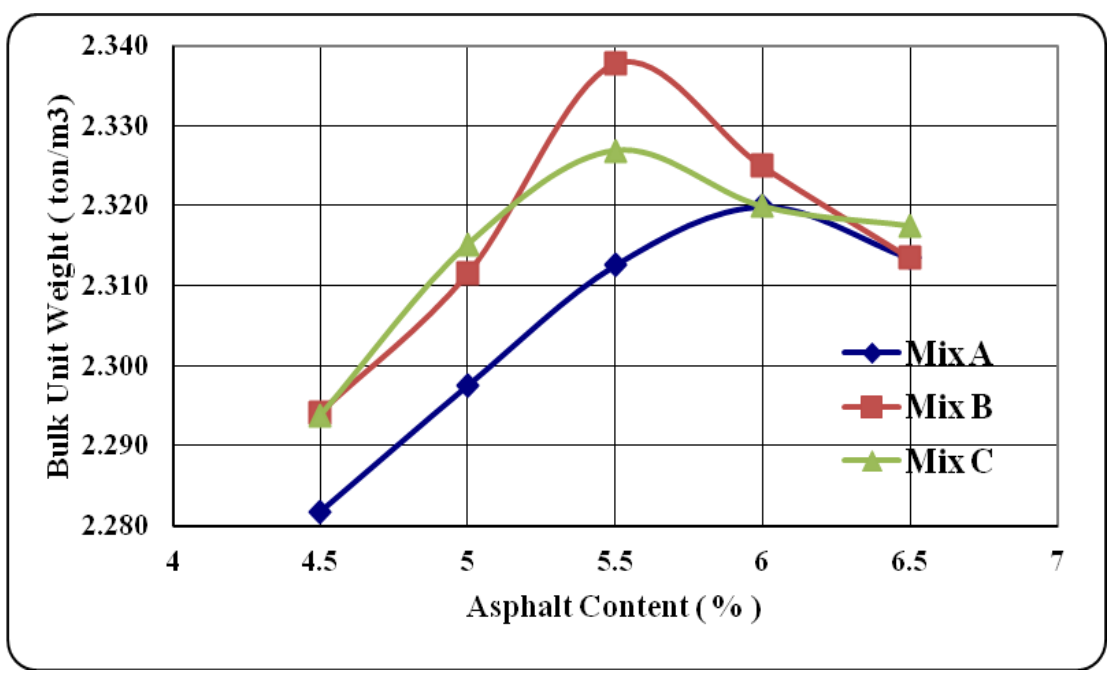

Fig. (2): Marshall Bulk Unit Weight for all Mixtures

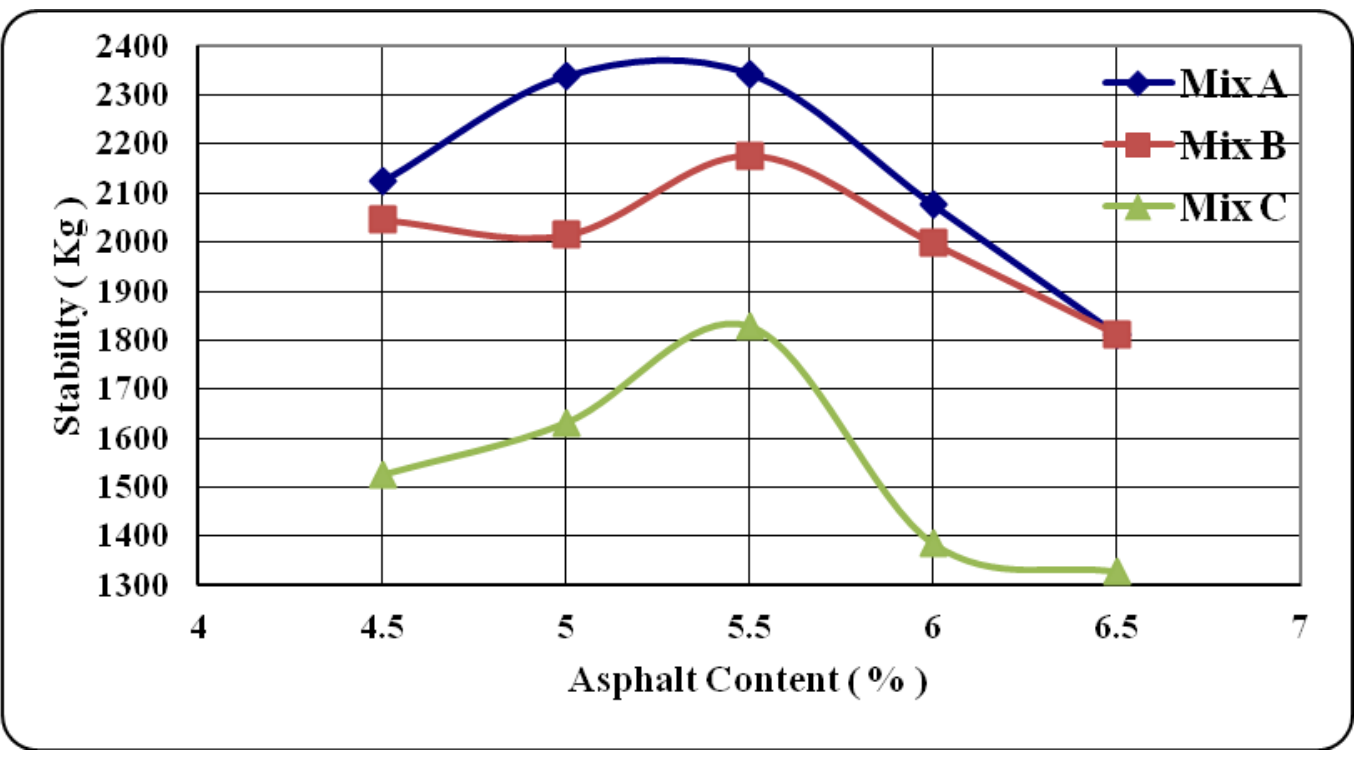

Fig. (3): Marshall Stability for all Mixtures

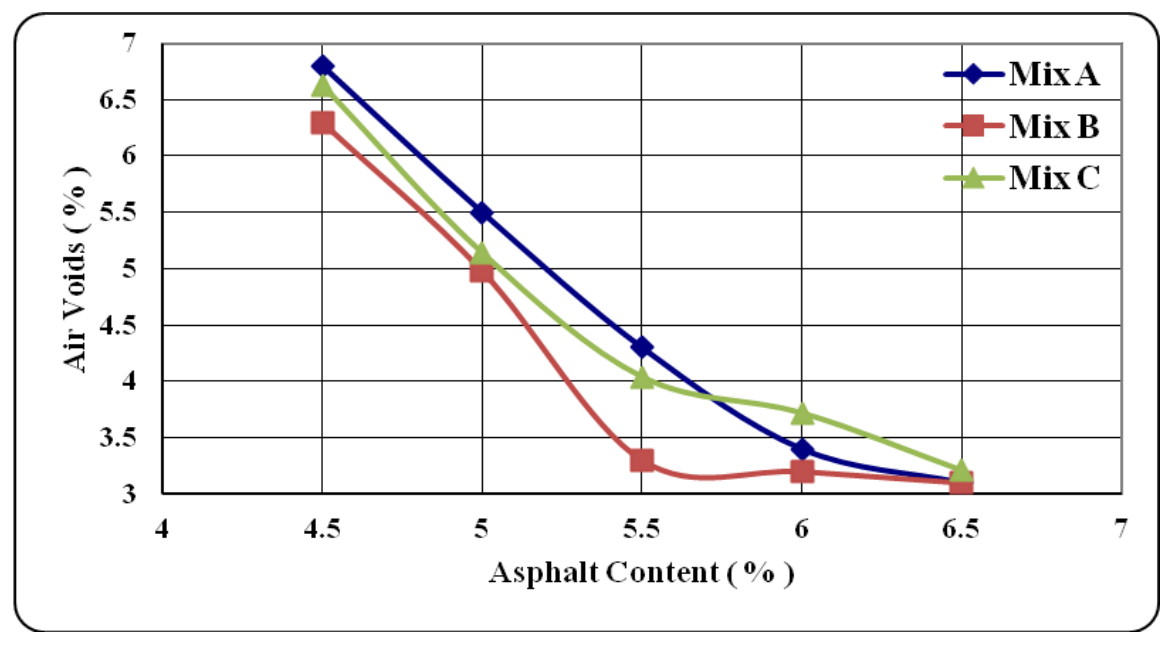



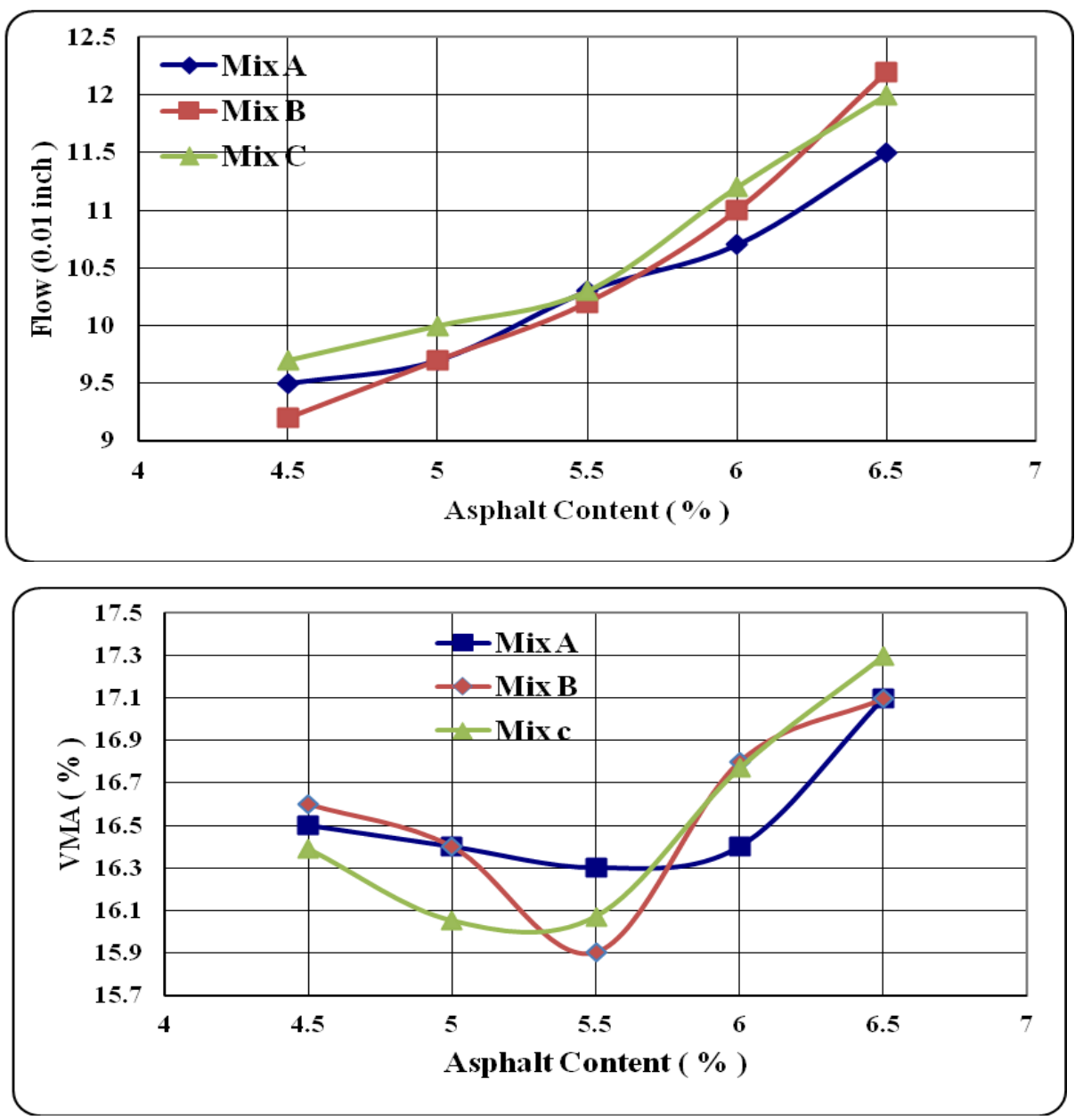

Figure (4,5, and 6): Air Voids, Flow, and VMA for all Mixtures

2. The flow value for all the mixtures are presented in Fig. 5 which indicated that most of the values are within the specifications limits.

Table (4): Selecting Optimum Asphalt Content Criteria from Marshall Design Charts for each Mix

\begin{tabular}{|c|c|c|c|}
\hline \multirow{2}{*}{ Test Method } & \multicolumn{3}{|c|}{ Mix } \\
\hline & A & B & $\mathbf{C}$ \\
\hline Asphalt Content @ Max. Density, (\%) & 6.00 & 5.50 & 5.50 \\
\hline Asphalt Content @ Max. Stability, (\%) & 5.30 & 5.50 & 5.50 \\
\hline Asphalt Content @ Optimum Voids (4\%), (\%) & 5.65 & 5.35 & 5.50 \\
\hline Average Asphalt Content, (\%) & 5.65 & 5.45 & 5.50 \\
\hline
\end{tabular}

3. Fig (2) shows the bulk density values for various mixtures as a function of RAP content. In this Fig, the bulk density increases with the increase in RAP content, this indicates that; with the presence of RAP more dense mixes will be produced as compared with no RAP mixes and this effect appears clearly with the increasing in RAP content. 
4. Fig (4) shows the relationship between the percent of air voids and RAP content. It can be noticed that percent of air voids decreases with the increase in percent of RAP content. This is an indication that the old asphalt in the RAP aggregate do not act and the old asphalt in the RAP contributed with new asphalt cement (AC) and result in increasing the asphalt percentage in the produced mix. And this leads to a reduction in percent of air voids for compacted specimen and consequently the bulk density of specimen increases.

5. Fig (6) shows voids in mineral aggregate (VMA) against RAP content. It can be noticed that percent of (VMA) decreases with the increase of RAP content. This reduction in (\% VMA) due to the decrease percent of air voids.

Table (5): Marshall Design Criteria

\begin{tabular}{|c|c|c|c|c|}
\hline \hline \multirow{2}{*}{ Test Properties } & \multicolumn{3}{|c|}{ Test Results @ OAC } & \multirow{2}{*}{ Specification Limits } \\
\cline { 2 - 4 } & Mix A & Mix B & Mix C & \\
\hline \hline Optimum Asphalt Content (OAC) (\%) & 5.65 & 5.45 & 5.50 & - \\
\hline Density (kg/cm $)$ & 2.316 & 2.336 & 2.326 & - \\
\hline Stability (lb) & 2325 & 2175 & 1829 & 1800 min. \\
\hline Air Voids (\%) & 4.00 & 3.35 & 4.04 & $3-5$ \\
\hline VMA (\%) & 16.30 & 15.90 & 16.07 & $16 \%$ \\
\hline Flow (0.01") & 10.40 & 10.1 & 10.30 & $8-14$ \\
\hline \hline
\end{tabular}

\section{CONCLUSIONS}

This paper presents a comparative study between the currently used hot asphalt mixes which use fresh aggregates and virgin asphalts and those mixes prepared using local RAP materials. Measurement of Marshall Test was conducted, compared and analyzed. The results of the conducted tests indicate that the use of RAP in hot mix asphalt is advantageous. These results agree with and support previous research findings. Based on the performed tests, the following conclusions can be drawn:

1. In laboratory the RAP mixtures designed using Marshall method perform the same or even better than the conventional mixtures.

2. Marshall stability decreases with the increasing of RAP content.

3. Increasing of the percent of RAP content produces decreasing of air voids and VMA. This increasing in RAP would produce an increase in bulk density, flow and VFA with the same increment in RAP content..

4. Results of marshall properties indicate that the amount of new binder in the RAP mixture can be reduced without any effect on the quality of the produced mixes.

5. Overall the local RAP gives better performance in hot mix asphalt.

6. Using RAP in design even up to $40 \%$ will help in conserving the natural resources, reducing the HMA price and improve the performance.

7.

\section{REFERENCES}

1. Al-Qadi, I.L., Elseifi, M., and Carpenter, S. H. (2007). Reclaimed Asphalt Pavement - A Literature Review, Project Report FHWA-ICT-07-001. Illinois Center for Transportation. University of Illinois at Urbana-Champaign, Illinois.

2. American Association of State Highway and Transportation Officials (AASHTO). 1988. Standard Specifications for Transportation Materials and Methods of Sampling and Testing, 19th Edition, Washington, D.C.

3. American Society of Testing and Materials (ASTM). 2000. Annual Book of ASTM Standards (03-04), West Conshohocken, PA. 
4. Asphalt Hot-Mix Recycling, Manual Series No. 20 (MS-20) Second Edition. The Asphalt Institute, 1986.

5. ARRA 2001. Basic Asphalt Recycling Manual. Asphalt Recycling and Reclaiming Association, USA.

6. Environmental Protection Agency and Federal Highway Administration (1993), "Recycling of Asphalt Pavements Using at Least 80 Percent Recycled Asphalt Pavement Engineering and Environmental Aspects of Recycled Materials for Highway Construction, Report No. FHWA-RD-93-088.

7. Federal Highway Administration. 2001. Reclaimed Asphalt Pavement User Guideline: Asphalt Concrete (Hot Recycling). Web page on the Turner-Fairbanks Highway Research Center web-site. http://www.tfhrc.gov/hnr20/ recycle/ waste/ rap132.htm; (Oct., 2007).

8. Huang, B. \& Vukosavljevic, D. (2006). Laboratory study of fatigue characteristics of HMA mixtures containing recycled asphalt pavement (RAP). The University of Tennessee, Knoxville.

9. Maupin G. W., Diefenderfer S. D., Gillespie J.S., 2008, Evaluation of Using Higher Percentages of Recycled Asphalt Pavement in Asphalt Mixes in Virginia, Virginia Transportation Research Council VTRC 08-R22, Virginia.

10. NAPA 2007. Recycling Hot Mix Asphalt Pavements. National Asphalt Pavement Association, IS 123, Lanham, MD.

11. Pereira, P., Oliveira, J, \& Picado-Santos, L.(2004).Mechanical characterization of hot mix recycled materials, International Journal of Pavement Engineering, 5 (4), 211 220. 